\title{
Repertórios interpretativos acerca do preconceito racial no futebol ${ }^{1}$
}

Andreza Silene Silva Ferreira. Universidade Federal da Paraíba

Eldo Lima Leite. Universidade Federal da Paraíba

Amanda Wanderley Leite de Sousa. Universidade Federal da Paraíba

José Luis Álvaro Estramiana. Universidad Complutense de Madrid

Ana Raquel Rosas Torres. Universidade Federal da Paraíba

\section{Resumo}

Neste trabalho objetivou-se analisar os repertórios interpretativos utilizados pelas pessoas para se posicionarem diante de situações de preconceito racial no futebol. Participaram 295 universitários, com idade média de 21 anos, sendo 37,1\% do sexo masculino e $62,9 \%$ do sexo feminino. Utilizou-se um questionário com uma história fictícia na qual um torcedor de um time de futebol xingava um jogador do time adversário com termos depreciativos relacionados à sua cor. Em seguida, perguntava-se se isso seria uma demonstração de preconceito e pedia-se para que a resposta fosse justificada. A análise lexical das justificativas mostrou que, das cinco classes encontradas, quatro apresentam a ideia de que o preconceito existe e apenas uma nega sua existência. Esses resultados são discutidos enfatizando o fato que o contexto do futebol se apresenta como um cenário propício para investigar expressões flagrantes de preconceito racial porque existe a justificativa plausível da competição.

Palavras-chave: preconceito racial no futebol; análise léxica; discriminação racial.

\begin{abstract}
Interpretative repertoires about racial prejudice in football Racial prejudice in football. The aim of this study was to analyze the interpretative repertoires that people use to position themselves for or against in relation to racial prejudice situations in football. 295 college students took part in this research, with a mean of 21 years old; $37.1 \%$ were male and $62.9 \%$ female. A questionnaire in which participants responded to questions about a fictitious situation in which a supporter insulted a player of the rival team because of the color of his skin was used. Immediately after respondents were asked to justify whether the situation presented could be considered as an example of racial prejudice. The lexical analysis performed showed that, out of the five classes found, four of them presented the idea that prejudice exists and only one denies its existence. These results are discussed stressing the fact that the context of football represents an excellent setting to research situations of flagrant racial prejudice since the competition acts as plausible justification.
\end{abstract}

Keywords: racial prejudice in football; lexical analysis; racial discrimination.

\section{Resumen}

Repertorios interpretativos acerca del prejuicio racial en el fútbol Prejuicio racial en el fútbol. El objetivo de este trabajo fue analizar los repertorios interpretativos utilizadas por las personas para posicionarse frente a situaciones de prejuicio racial en el fútbol. Participaron 295 estudiantes universitarios, con una edad media de 21 años, de los cuales un 37,1\% eran hombres y un $62,9 \%$ eran mujeres. Se utilizó un cuestionario con una historia ficticia en la cual un aficionado de un equipo de fútbol insultaba a un jugador del equipo adversario con frases despectivas relativas al color de su piel. Posteriormente, se preguntaba sobre si dichas expresiones podrían considerarse como una demostración de prejuicio y se pedía que las respuestas fuesen explicadas. El análisis lexical de las justificaciones dadas mostró que, de las cinco clases encontradas, cuatro presentan la idea de que el prejuicio existe y apenas una niega su existencia. Estos resultados son discutidos enfatizando el hecho de que el contexto del fútbol se presenta como un escenario propicio para investigar las expresiones flagrantes de prejuicio racial porque existe la justificación plausible de la competición.

Palabras clave: prejuicio racial en el fútbol; análisis léxico; discriminación racial. 
O futebol é um fenômeno sociocultural que transcende a dinâmica esportiva e envolve a produção de significados e emoções. Seu funcionamento simbólico e ritualístico exerce um papel de orientação para seus adeptos levando-os a comportamentos que geralmente não realizariam se estivessem em outros contextos (Dumning \& Elias, 1992). Desta forma, o contexto do futebol pode ser considerado um cenário propício para o estudo do preconceito racial por se tratar de uma situação na qual expressões flagrantes desse fenômeno são justificáveis como sendo produto da competição. Entretanto, o que tem sido demonstrado é que piadas e brincadeiras só se revestem de conteúdos racistas se houver uma atitude preconceituosa latente, que refletem o pensamento e as interações simbólicas desenvolvidas no contexto social mais amplo (Ferreira et al., 2017).

Historicamente, no Brasil, as relações inter-raciais têm sido caracterizadas pela miscigenação que, por sua vez, alicerçou a construção do mito da democracia racial. Esse mito tem sido utilizado como mecanismo ideológico na legitimação de processos de exclusão e desigualdade raciais por negar, por um lado, a existência de diferenças entre negros e brancos decorrentes do período de escravidão e, por outro lado, fundamentar a ideia de que situações de discriminação têm outra razão que não o preconceito (Camino, Gouveia; Maia; Paz, \& Santos 2013; Ferreira et al., 2017; Guimarães, 2002).

Nesse sentido, Telles (2003) argumenta que a ideologia racial conduz a interpretações da discriminação como resultante das diferenças de classes sociais, e não de diferenças raciais. Ao analisar a desigualdade racial no Brasil, esse autor observou que a estrutura socioeconômica brasileira é dividida em função de categorias raciais e que os negros (pretos e pardos) representariam a pobreza, enquanto os brancos ocupariam as camadas sociais mais altas. De fato, dados do Instituto Brasileiro de Geografia e Estatística (IBGE) (2014) mostram que os negros ainda ocupam as camadas sociais mais baixas de nossa população. Assim sendo, a categoria racial indicaria uma condição de vantagens para os brancos e de exclusão e desvantagem para os negros (Carone, 2002; Munanga, 2001). Neste caso, a condição social do negro não se caracterizaria apenas pelo aspecto econômico, mas estaria associada aos processos de exclusão social, decorrentes da discriminação nas quais se desenvolve o preconceito (Camino, Silva,
Machado, \& Pereira, 2001). No Brasil, essas desigualdades se encontram muitas vezes camufladas, o que dificultaria seu estudo e a análise de suas consequências psicossociais (Carone, 2002).

O interesse pelo preconceito racial é antigo e surge simultaneamente na psicologia social como na sociologia (Allport, 1954; Blumer, 1958) como uma resposta aos eventos históricos e sociais ocorridos na primeira metade do século XX (Devine et al., 2003, p. 198). Na psicologia social, de modo geral, o preconceito é concebido como uma atitude negativa direcionada a membros de determinados grupos sociais (Allport, 1954; Devine, Plant, \& Blair, 2003). Já na sociologia, esse fenômeno é visto mais como a consciência da posição social do grupo racial do que como o conjunto de sentimentos que os membros de um grupo racial têm face aos membros de outro grupo racial (Bergere, 1996; Blumer, 1958). Note-se que, na primeira definição enfatiza-se os processos psicológicos, enquanto que a segunda insere o preconceito racial em um contexto social e simbólico de relações intergrupais (Rodriguez, 1996).

Perspectivas mais atuais sobre esse fenômeno, no entanto, tentam articular processos psicológicos com os contextos sociais mais amplos. Brown (2010), por exemplo, afirma que o preconceito não se apresenta apenas em forma de avaliações e crenças negativas sobre os grupos, mas está diretamente relacionado à discriminação, que é definida como um comportamento diferenciado e dirigido a indivíduos ou grupos como consequência da pertença a uma categoria (Brewer, 1994, p. 371). Neste sentido, a discriminação é a manifestação comportamental do preconceito. São ações que objetivam preservar ou criar vantagens de um grupo sobre outro grupo, bem como legitimar as desigualdades sociais (Schucman, 2014) e que acontecem nas relações intergrupais existentes em um determinado momento histórico. Assim sendo, tanto o preconceito racial como a discriminação relacionada a ele têm que ser compreendidos levando em consideração características sócio-históricas da sociedade na qual eles ocorrem (Batista, Leite, Torres, \& Camino 2014; Camino et al., 2001; Carone, 2002). A concepção de preconceito racial utilizada neste trabalho articula elementos psicológicos (atitudes individuais) e sociológicos (o contexto social e simbólico de uma competição esportiva).

Finalmente, também é importante diferenciar o preconceito racial do racismo, que segundo Lima e Vala 
(2004) se constitui num processo de hierarquização, exclusão e discriminação contra membros de determinadas categorias sociais cujo critério de diferenciação social é de caráter biológico (Helms \& Talleyrand, 1997). Neste sentido, o racismo seria uma maneira de transformar características culturais em biológicas (Guimarães, 1999) com o objetivo de transformar o preconceito racial em práticas culturais e institucionais de dominação de um grupo sobre outro (Jones, 1997).

Diversas pesquisas têm buscado evidenciar os diversos contextos nos quais o preconceito racial e a discriminação contra os negros se manifestam (Álvaro et al., 2015; Batista et al., 2014; Camino , 2014; Camino, Álvaro, Torres, Garrido, Morais, \& Barbosa, 2013; Camino, Gouveia, Maia, Paz, \& Santos, 2013). Em conjunto, essas pesquisas demonstram que, embora as normas antidiscriminatórias coíbam expressões abertas do preconceito racial observa-se que elas não são suficientes para impedirem suas manifestações. Assim, em nossa sociedade alguns comportamentos preconceituosos parecem estar difundidos no tecido social e, em alguns contextos, escapam do controle normativo (Munanga, 2001). Entre estes contextos encontra-se o futebol brasileiro. Como exemplo, temos visto que a mídia divulga sistematicamente eventos que mostram torcedores xingando de "macaco" ou "preto fedido" jogadores negros do time adversário. No entanto, isso tende a ser visto como brincadeiras próprias do contexto de disputa do futebol e não como expressões de preconceito racial (Barradas \& Lopes, 2013; Cervi, 2014; Giglio et al., 2014; N. Santos, Capraro, \& Lise, 2010; T. C. Santos, 2014). Esse tipo de manifestações, nitidamente preconceituosas, podem ser consideradas como o componente atitudinal do racismo cordial, que é típico do Brasil (Lima \& Vala, 2004). No entanto, essas "brincadeiras" têm, sem dúvida, o objetivo claro de rebaixar os jogadores pelo fato de serem negros.

De fato, no Brasil observa-se uma discrepância entre o discurso autorreferido e o discurso hetero-referido no que diz respeito ao preconceito racial. As pessoas reconhecem que existe preconceito no país, mas não assumem a responsabilidade por esse preconceito (Batista et al., 2014; Camino et al., 2001). Esse tipo de discurso ideológico se insere numa perspectiva de representações justificadoras dos processos de discriminação contra grupos minoritários (Lima-Nunes \&
Camino, 2011). Assim, as piadas e brincadeiras baseadas nas características fenotípicas formariam as bases do que diferentes autores denominaram de racismo cordial (Camino et al., 2001; Lima \& Vala, 2004; Turra $\&$ Venturi, 1995) e que, na realidade, nada tem de cordial. Assim, o contexto do futebol nos oferece um contexto ideal para analisar o componente atitudinal desse racismo aparentemente cordial.

De acordo com Wetherell e Potter (1996), as pessoas tendem a adaptar seus discursos a determinadas situações e contextos conforme as normas sociais vigentes. Neste sentido, as pessoas exibiriam diferentes atitudes, dependendo do tipo de discurso considerado mais adequado a cada situação. Potter e Wetherel (1987) propõem o conceito de repertório interpretativo, concebido como um conjunto de termos, lugares comuns e descrições usadas para se referir a uma mesma situação. Estes repertórios se caracterizariam precisamente pela variabilidade, e não pelo consenso. Essas ideias se assemelham às propostas por Doise (1990), no campo das representações sociais, em que repertórios se organizam por meio dos princípios que atribuem significado tanto aos aspectos consensuais quanto aos divergentes do campo representacional. Diante disso, consideramos relevante analisar os repertórios interpretativos a partir dos "princípios organizadores das tomadas de posição ligadas a inserções específicas em um conjunto de relações sociais e que organizam os processos simbólicos que intervêm nessas relações" (Doise, 1990).

Tendo com marcos teóricos as ideias expostas, o objetivo deste trabalho é analisar os repertórios interpretativos que as pessoas utilizam para se posicionarem diante de situações de preconceito racial no futebol e quais princípios organizam essa tomada de posição.

\section{Método}

Trata-se de um estudo qualitativo, descritivo, de caráter exploratório.

\section{Participantes}

Participaram deste estudo 295 estudantes de uma universidade pública da Paraíba, com idades média de $M=21 ; D P=6,01$, sendo $37,1 \%$ do sexo masculino e $62,9 \%$ do sexo feminino. Referente à cor, $28,9 \%$ eram brancos, $62,6 \%$ eram pardos e $8,5 \%$ eram pretos. A amostra foi não-probabilística por conveniência. 


\section{Procedimentos}

Os estudantes foram abordados em sala de aula mediante autorização do professor e solicitados a participarem da pesquisa. Após o rapport, os participantes assinaram o Termo de Consentimento Livre e Esclarecido. Foram atendidas todas as recomendações éticas prescritos na resolução 466/12 do Conselho Nacional de Saúde, Protocolo 035/15. CAAE: 41024815.0.0000.5188.

\section{Instrumento}

Utilizou-se um questionário com uma história fictícia, na qual um torcedor de um time de futebol xingava um jogador do time adversário com termos depreciativos relacionados à sua cor (e.g. macaco, negro fedido). Em consequência disso, o jogador que foi alvo dos xingamentos, por meio do seu advogado, processou o torcedor identificado e pediu uma indenização financeira pelo ocorrido. Após ler a história o participante respondia a um item, em formato Likert de sete pontos, referente à frequência dessa situação no futebol brasileiro. Em seguida, era solicitado que escrevesse um texto justificando sua resposta.

Posteriormente, ele respondia as seguintes questões: Em sua opinião, esta situação pode ser considerada como um ato racista? Em sua opinião, a sociedade vê esta situação como um ato racista? Em ambas as perguntas o participante deveria justificar sua opinião. Em seguida o participante informava, por meio de uma escala Likert de sete pontos, o grau de concordância com a indenização pedida pelo advogado do jogador. Logo após, o participante que concordasse com a indenização, indicava um valor que achasse justo entre $\mathrm{R} \$ 1.000,00$ e $\mathrm{R} \$ 100.000,00$. Por fim, o participante respondia a questões de caráter sociodemográfico como sexo, core idade.

\section{Análise dos Dados}

As questões abertas foram analisadas por meio da Análise Léxica utilizando o software Iramuteq (Interface de R pour lês Analyses Multidimensionnelles de Textes et de Questionnaires) desenvolvido por Pierre Ratinaud (2009). Nas análises léxicas clássicas, o software identifica os textos (Unidades de Contextos Iniciais - UCI), transformando-os em segmentos de textos (Unidades de Contextos Elementares - UCE), realiza a pesquisa do vocabulário e reduz as palavras com base em suas raízes, criando formas reduzidas e complementares (Camargo \& Justo, 2013). O Iramuteq também fornece uma Análise Fatorial de Correspondência (AFC) na qual explana as relações espaciais entre as classes, demonstrando as aproximações e afastamentos entre os repertórios interpretativos encontrados.

\section{Resultados}

\section{Análise da Frequência do Preconceito Racial no Futebol}

A maioria dos participantes (63\%) acredita que situações de preconceito racial são muito frequentes no futebol brasileiro. Após a redução dos vocábulos às suas raízes, a análise léxica das justificativas dadas para esse posicionamento, obteve-se um total de 294 Unidades de Segmento de Textos (UCEs). A Classificação Hierárquica Descendente (CHD) demonstra que a partição do corpus de análise derivou cinco classes distintas (Figura 1). A classe 1 equivalente a 22,1\% das UCEs, a classe $5,17,8 \%$ das UCEs, a classe $3,19,1 \%$ das UCEs, a classe $4,22,1 \%$ das UCEs e a classe 2 , equivalente a $19,1 \%$.

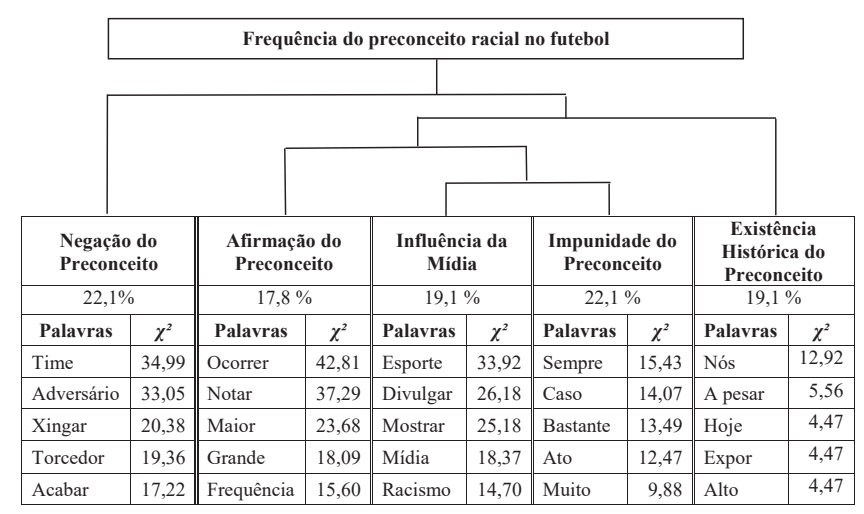

Figura 1. Análise das Justificativas da Frequência do Preconceito Racial no Contexto do Futebol.

A classe 1, Negação do Preconceito, demonstra que o uso dos xingamentos no futebol é consequência inerente à disputa e são utilizados para atingir o adversário emocionalmente e assim "atrapalhar" seu desempenho. Exemplos de repertórios interpretativos mais representativos desta classe são: "Os torcedores utilizam vários fatores para atrapalhar os adversários [...]; "acredito que na maioria dos casos não é pelo preconceito e sim para desestabilizar o psicológico do jogador".

A classe 5, Afirmação do Preconceito, refere-se ao preconceito racial no futebol como consequência da prática em diversas esferas sociais e das ações de alguns grupos. Exemplos de repertórios interpretativos mais representativos desta classe são: "A situação que ocorre no futebol decorre de um problema social maior, 
o que determina a conduta dentro do estádio em grupo é a conduta fora dele"; "A prática do racismo em nosso país ainda é grande inclusive em estádios de futebol".

A classe 3, Influência da Mídia, apresenta a ideia de que à exibição do preconceito racial na mídia está condicionada à importância dos jogadores envolvidos, assim, enfatiza-se algumas situações e ignoram outras. Os discursos mais representativos desta classe são: "Sendo que muitas vezes alguns podem não ser divulgados pela mídia, pois os jogadores ofendidos não são protagonistas no esporte"; "a mídia divulga o que considera mais importante, como se racismo ofendesse a uns e outros não".

A classe 4, Impunidade do Preconceito, assinala que os xingamentos referentes à cor são cada vez mais frequentes no futebol e apontam a da falta de punição como responsável por este aumento. Exemplos de repertórios interpretativos mais representativos desta classe são: "Atualmente a questão do racismo no futebol vem aumentando bastante não só no futebol brasileiro, mas no mundial"; "Esta situação é muito frequente no futebol brasileiro, pois não há punições mais severas para essas pessoas".

Por fim, a classe 2, Existência Histórica do Preconceito, demonstra que a miscigenação racial do país não é suficiente para suprimir o preconceito racial, presente desde a colonização. Exemplos de repertórios interpretativos mais representativos desta classe são: "Vivemos em um país em que infelizmente o preconceito é algo comum [...] mesmo o Brasil sendo um país de maioria descendente negra"; "Isso é um problema que ainda atinge diretamente a nossa população [...] o racismo está presente desde nossa origem colonial".

Seguindo Doise (1990) sobre os princípios organizadores das tomadas de posição, analisaremos, a partir dos eixos horizontal e vertical, a lógica que organiza as classes por meio das distâncias entre os discursos (Figura 2).

Ao analisar o plano fatorial, observa-se que o eixo horizontal dividiu os repertórios interpretativos em função da ideia da existência e da não existência do preconceito. As classes 5 (Afirmação do Preconceito), 3 (Influência da Mídia), 4 (Impunidade do Preconceito) e 2 (Existência Histórica do Preconceito) apresentam a ideia de que o preconceito existe e que seria herança do período colonial, das relações desiguais entre os grupos e da impunidade da prática do preconceito racial. Observa-se que há uma maior sobreposição entre as classes 5, 3 e 4, o que não acontece com a classe 2, que apesar de compartilhar alguns elementos com essas classes, ainda mantém um conjunto de elementos claramente diferenciados. Tal proximidade pode ser explicada pelo fato de todas elas fazerem referência tanto à afirmação, quanto à difusão midiática e impunidade do preconceito. Já a classe 1 (Negação do Preconceito) apresenta a ideia de que o preconceito racial, nesta situação, não existiria, sendo consequência da disputa entre as equipes.

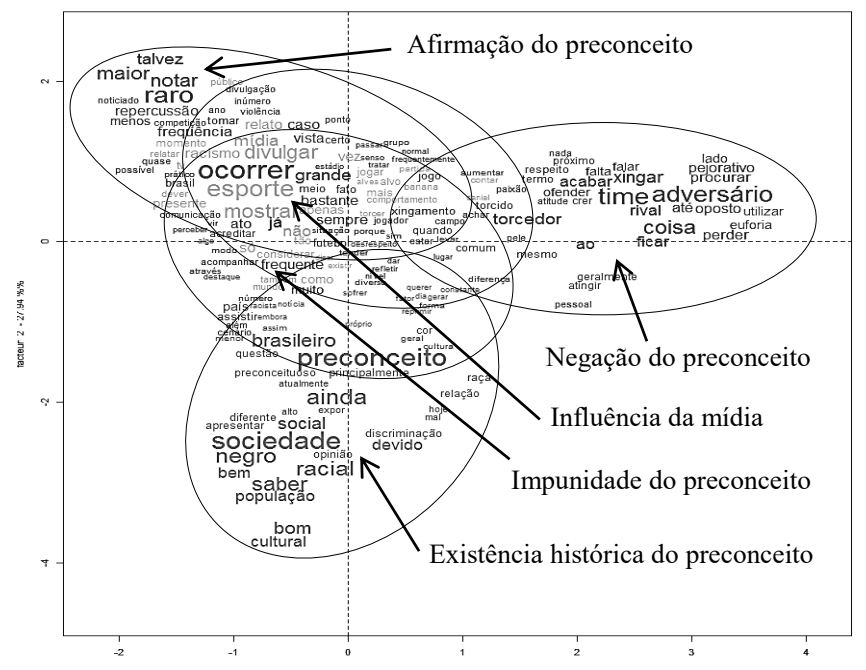

Figura 2. AFC das Classes Discursivas acerca da Frequência do Preconceito Racial no Futebol.

Por outro lado, o eixo vertical dividiu os repertórios interpretativos em função de o preconceito racial ser ou um fenômeno histórico ou atual. As classes 1 (Negação do Preconceito), 5 (Afirmação do Preconceito), 3 (Influência da Mídia) e 4 (Impunidade do Preconceito) referem-se ao preconceito racial como um fenômeno atual, uma vez que além de existir, ele é difundido por meio da mídia. A classe 2 (Existência Histórica do Preconceito) aponta a existência do preconceito racial como um fenômeno decorrente do período colonial, onde os negros eram tidos como mercadoria usada no regime escravocrata.

\section{Análise da Resposta acerca do Caso Ser um Ato Racista}

Em relação à questão sobre o participante considerar o caso como um ato racista, 93,6\% dos participantes consideraram um ato racista. A análise léxica das 
justificativas para essa opinião mostra um total de 289 Unidades de Segmento de Textos (UCE). A CHD,após a partição do corpus de análise, apresentou cinco classes distintas (Figura 3). A classe 1 equivale a 17,8\% das UCEs, a classe $2,20,7 \%$ das UCEs, a classe $3,16 \%$ das UCEs, a classe $4,17,4 \%$ das UCEs, e a classe $5,28,2 \%$ das UCEs.

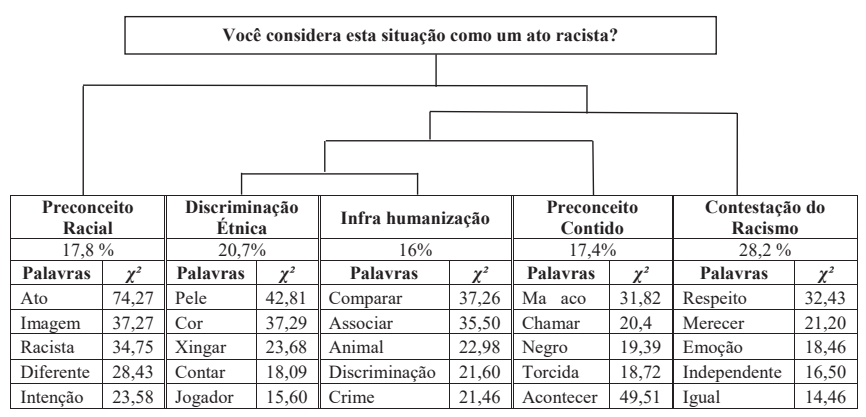

Figura 3. Análise das Justificativas da Consideração do Caso como um Ato Racista na Perspectiva do Participante.

A classe 1, Preconceito Racial, diz respeito aos insultos e provocações proferidas acerca da cor do alvo com a intenção de depreciar a imagem do negro. Exemplos de repertórios interpretativos mais representativos desta classe são: "Referir a uma pessoa de maneira pejorativa com base na cor da pele do outro é um ato em si racista e discriminante"; "A partir do momento que eu quero denegrir a imagem de uma pessoa simplesmente pela cor de sua pele isto pode ser considerado um ato racista".

A classe 2, Discriminação Racial, refere-se ao uso de conteúdos raciais por pessoas que se consideram superiores e utilizam a humilhação para afirmar esta suposta superioridade. Exemplos de repertórios interpretativos mais representativos desta classe são: Sim, pois à medida que você humilha a imagem do outro menosprezando sua cor, cultura, religião, entre outros, se torna racista "; "Sim, porque muitas pessoas utilizam esse termo porque acham que os negros são inferiores aos da pele branca".

A classe 3 , infra humanização, refere-se à ideia de desumanização, uma vez que jogador é comparado a um macaco. As expressões depreciativas teriam como objetivo envergonhar e desonrar o indivíduo. Exemplos de repertórios interpretativos mais representativos desta classe são: "Eles estavam associando a palavra macaco de forma pejorativa para simbolizar um ser menos evoluído"; "Porque é considerada uma ofensa a dignidade humana a comparação do homem a condição de animal".
A classe 4, Preconceito Contido, apresenta a ideia de que é comum se referir ao negro de maneira preconceituosa, mas que esta atitude seria caraterizada como um "racismo parcial". Exemplos de repertórios interpretativos mais representativos desta classe são: "Como bem sabemos a expressão macacos aqui no Brasil atualmente se dá por algumas pessoas serem de cor negra [...] acontecendo então um racismo parcial"; "Nem sempre trata-se de ato racista [...] depende do contexto".

A classe 5 , Contestação do Racismo, apresenta a ideia de que o uso do termo racismo é inapropriado para caracterizar a situação, sendo mais adequado o uso da expressão falta de respeito. Exemplos de repertórios interpretativos mais representativos desta classe são: "Embora eu acredite que o termo racista não seja o mais apropriado [...] todos somos iguais e caráter não é definido pela cor da pele"; "Pois fazer associações desse tipo é totalmente antiético e falta de respeito".

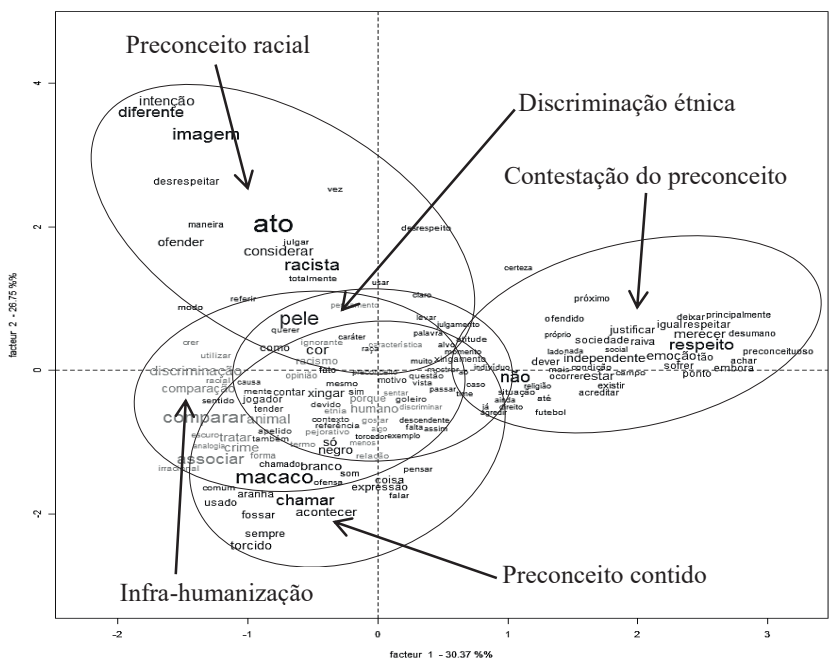

Figura 4. AFC das Classes Discursivas sobre a Consideração do Caso como um Ato Racista na Perspectiva do Participante.

Ao analisar o plano fatorial (Figura 4), observa-se que o eixo horizontal dividiu os discursos em função da afirmação do racismo e da inapropriação do termo racismo para esta situação. As classes 1 (Preconceito Racial), 2 (Discriminação Racial), 3 (Infra humanização) apresentam a ideia de que as manifestações preconceituosas dirigidas aos negros têm a intenção de reduzira humanidade do negro, uma vez que este é tratado de forma inferior. Já a classe 4 (Preconceito Contido), embora afirme a existência do preconceito racial, apresenta um discurso amenizador da 
situação caracterizando-o como um "racismo parcial". Observa-se também que as classes 2 e 3 ficaram sobrepostas no plano. Esta proximidade pode ser explicada pelo fato dessas classes compartilharem, em seus discursos, ideias que remetem à desvalorização do negro, seja pela infra humanização ou pela inferiorização do negro em relação ao branco.

Noutra perspectiva, a classe 5 (Contestação do Racismo) apresenta o discurso de que a igualdade é um direito que assiste a todos. Porém, ao fazerem referência à situação em tela, os discursos apontam para uma inadequação do termo racismo, indicando uma não atribuição de preconceito racial aos comportamentos dos torcedores e uma não violação ao direito da igualdade de tratamento.

No eixo vertical, os discursos foram separados em função da intensidade da expressão do preconceito racial, opondo discursos que consideram as expressões como uma situação grave a discursos que minimizam essa gravidade. As classes 1 (Preconceito Racial), 2 (Discriminação Racial), 3 (Infra humanização) fazem referência à existência do preconceito como sendo algo danoso e com propósito de inferiorizar o grupo dos negros. Já a classe 4 (Preconceito Contido), apesar dos discursos fazerem referência à maneira como os negros são tratados de forma preconceituosa, defendem a ideia de que tais manifestações preconceituosas não são tão graves. A classe 5 (Contestação do Racismo) encontra-se mais centralizada e, embora compartilhe de conteúdos de ambos os posicionamentos, aproxima-se mais dos significados da classe 4 por tender a uma atenuação da manifestação do preconceito racial.

\section{Justificativa do Caso como um Ato Racista para a Sociedade}

Em relação à questão se a sociedade considera a situação como um ato racista, $84,2 \%$ dos participantes responderam afirmativamente. A análise léxica após a redução dos vocábulos às suas raízes, apresentou um total de 286 Unidades de Segmento de Textos (UCE).A CHD demonstra que a partição do corpus de análise derivou cinco classes distintas (Figura 5). A classe 5 representando20,5\% das UCEs, a classe $1,21,6 \%$ das UCEs, a classe $4,21,6 \%$ das UCEs, a classe $2,22 \%$ das UCEs, e a classe $3,14,3 \%$ das UCEs.

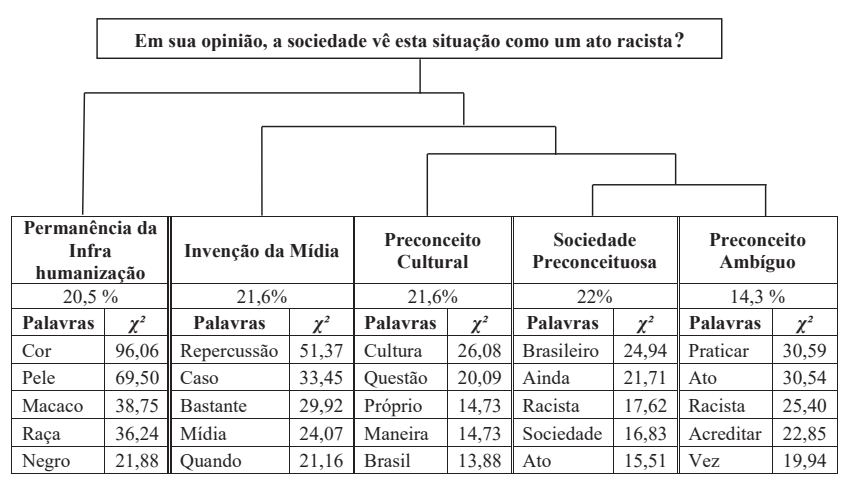

Figura 5. Análise das justificativas da consideração do caso como um ato racista quando os participantes falam pela sociedade.

A classe 5, denominada Permanência da Infra Humanização, apresenta a ideia de que a comparação entre o negro e o macaco, tendo por base a cor da pele, tem como intuito inferiorizar o negro. Exemplos de repertórios interpretativos mais representativos desta classe são: "O negro é geralmente associado a uma raça inferior e a ligação com o macaco quer dizer que não tem inteligência suficiente"; "Pois chamar alguém de macaco está relacionado às características de um macaco como a cor da pele".

A classe 1 , Invenção da Mídia, traz a ideia de que o preconceito racial no futebol é midiático, sendo a ênfase dada aos casos que geram a noção de racismo. Exemplos de repertórios interpretativos mais representativos desta classe são: "A mídia difunde essa ideia como algo racista"; "Sim porque na maioria das vezes quando ocorre uma situação assim a mídia cai em cima e considera como sendo racismo".

A classe 4, Preconceito Cultural, refere-se à naturalização do preconceito racial na sociedade brasileira, sendo visto como parte da cultura e caracterizadas como brincadeiras inconsequentes. Exemplos de repertórios interpretativos mais representativos desta classe são: "Há em nossa cultura uma tendência a classificar como uma brincadeira"; "É mais uma questão de moralismo do que racismo [...] o racismo está impregnado em nossa cultura".

A classe 2, Sociedade Preconceituosa, refere-se ao preconceito racial como algo recorrente e presente em todas as camadas sociais. Neste sentido, como faz parte do cotidiano do brasileiro, as manifestações preconceituosas são frequentemente expressadas de forma espontânea. Exemplos de repertórios interpretativos mais representativos desta classe são: "Pois isso ocorre com frequência tanto no esporte como no dia a dia"; "Pois além da falta de esclarecimento da maior 
parcela da sociedade sobre o assunto é comum o fato disso acontecer em vários setores da vida social".

A classe 3 , Preconceito Ambíguo, refere-se à prática do racismo de forma ambivalente, evidenciando tanto o combate como a negligência a manifestações preconceituosas, apontando a falta de enfrentamento desta situação. Exemplos de repertórios interpretativos mais representativos desta classe são: "É de consciência geral que estes insultos são atos racistas, porém isto não inibe a população de praticá-los"; "A sociedade vê como um ato racista mesmo que muitas das vezes não fazem nada para combatê-lo [...]".

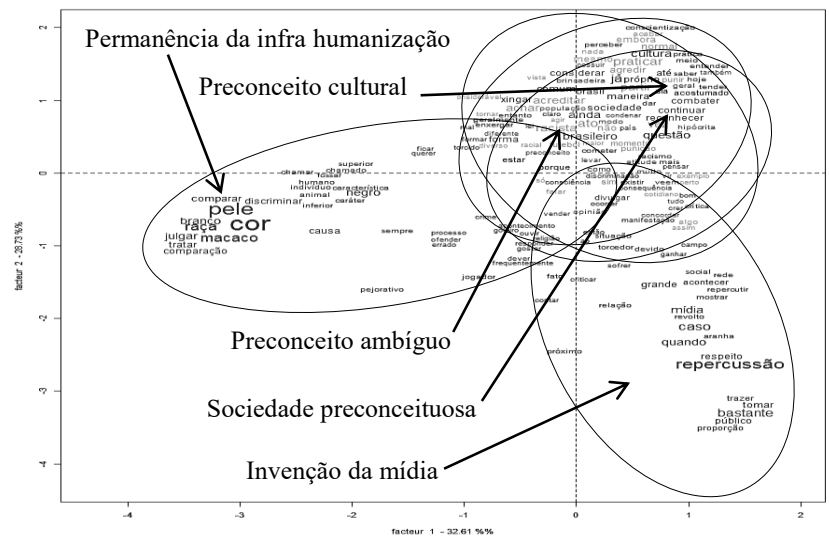

Figura 6. AFC das Classes Discursivas sobre a Consideração do Caso como um Ato Racistaquando os Participantes Falam pela Sociedade.

Ao analisar o eixo horizontal (Figura 6), pode-se observar que os discursos fazem referência ao preconceito sofrido pelos negros. A classe 5 (Permanência da Infra humanização) tem como ideia principal o compartilhamento de características entre o negro e o macaco, evidenciando, desta forma, o status inferior do negro enquanto ser humano. Por outro lado, os discursos das classes 4 (Preconceito Cultural), 2 (Sociedade Preconceituosa) e 3 (Preconceito Ambíguo) apontam o preconceito racial sofrido pelos negros como sendo algo cultural e comum no Brasil.

No eixo vertical, os discursos podem ser categorizados em função da existência e não existência do preconceito racial. As classes 4 (Preconceito Cultural), 2 (Sociedade Preconceituosa), 3 (Preconceito Ambíguo) e 5 (Permanência da Infra humanização) apresentam a ideia de que preconceito racial existe e que é tanto um produto da diferença de raças quanto um fenômeno comum da sociedade e cultura brasileira. Contrária a esta ideia, a classe 1 (Invenção da Mídia) apresenta os discursos que defendem que o preconceito racial, em nossa sociedade, não é devido às relações grupais, mas é um fenômeno construído e difundido pela mídia, de modo que se não houvesse tal divulgação, não haveria menções a tal fenômeno.

De um modo geral, as justificativas concernentes às três questões apresentam discursos semelhantes nos quais admitem a existência do preconceito racial na atitude do torcedor, mas ao mesmo tempo, relativizam a gravidade e as consequências dessa atitude, na medida em que as veem com um processo natural e inerente à própria sociedade brasileira. Diante disso, objetivou-se verificar se estes posicionamentos estariam refletidos na atribuição de valor a uma suposta indenização pedida pelo jogador. Neste sentido, buscou-se verificar a associação entre a percepção do racismo e o valor da indenização. Para tanto, os participantes foram agrupados de acordo com o valor atribuído à indenização em duas categorias, baixa e alta, por meio do critério da mediana.

Os resultados demonstraram que, dos $93,6 \%$ dos participantes que consideraram a situação como um ato racista, $42,4 \%$ atribuiu à indenização um valor inferior ou equivalente a $\mathrm{R} \$ 5.000$, bem abaixo do valor máximo possível, uma vez que esses valores variavam de $R \$ 1.000,00$ a $R \$ 100.000,00$. Estes resultados refletem repertórios interpretativos presentes nas classes 4 (Preconceito Contido), 1 (Invenção da Mídia) e 5 (Contestação do Racismo), uma vez que o preconceito racial é percebido, mas diante de ações de caráter punitivo ou reparatório, os indivíduos tendem a minimizar sua gravidade.

\section{Discussão}

Este trabalho teve como objetivo analisar os repertórios interpretativos que as pessoas utilizam para se posicionarem diante de uma situação de preconceito racial no futebol e quais princípios organizam essa tomada de posição. Os resultados demonstraram que os participantes, de um modo geral, admitem a existência do preconceito racial no futebol. No entanto, os princípios que ancoram essa tomada de posição diferem entre eles.

Por um lado, acredita-se que o preconceito racial no futebol é decorrente do histórico de discriminação do negro que vem ocorrendo desde a colonização e deve ser combatido. Essas ideias ancoram-se em três princípios: a) a existência do preconceito; b) seu aspecto histórico e c) na gravidade das manifestações do preconceito racial tanto no futebol como na sociedade como um todo. Esses repertórios interpretativos 
evidenciam o aspecto antinormativo e atual do preconceito racial em nossa sociedade (Munanga, 2001).

Por outro lado, alguns repertórios interpretativos apresentam opiniões que tendem a rejeitar ou racionalizar a existência do preconceito racial no futebol, na medida em que ele é considerado um artefato midiático ou apenas falta de respeito. Esses posicionamentos ancoram-se em ideias que negam a existência do preconceito racial no futebol, em seu aspecto atual e no uso do termo de forma inapropriada. Esses repertórios, como construções sociais, tendem a legitimar e auxiliam na manutenção das desigualdades raciais entre brancos e negros (Camino et al., 2001).

Essa distinção nos argumentos apresentados decorre da variabilidade dos repertórios referentes ao preconceito racial no futebol e das divergências observadas na forma como os participantes representam este fenômeno (Doise, 1990; Potter \& Wetherel, 1987). Embora o contexto ritualístico do futebol permita a expressão de significados e emoções diversas (Cervi, 2014; Dumning \& Elias, 1992; Giglio et al., 2014), o reconhecimento de que determinadas manifestações consideradas como brincadeiras e insultos, próprios do contexto do futebol, são manifestações do preconceito racial, pode ajudar a desmistificar a ideia de que no futebol, no calor das emoções, tudo está justificado pelo contexto da disputa (Ferreira et al., 2017).

\section{Considerações finais}

A relevância deste trabalho consiste na identificação dos princípios que organizam os posicionamentos frente ao preconceito racial em nossa sociedade e refletir como o contexto do futebol permite a expressão de preconceitos que não se ocorreriam em outros contextos. Neste sentido, este trabalho também permitiu detectar um cenário no qual a manifestação do preconceito racial expresso por meio de xingamentos racistas pretende parecer como algo justificável na medida que tenta legitimar os xingamentos como uma característica intrínseca à própria dinâmica da competição, como se fosse um lance aceitável do próprio jogo.

Dito de outra forma, o que os resultados aqui apresentados mostram é que "o racismo, a despeito de todas as leis antidiscriminatórias e da norma politicamente correta da indesejabilidade do preconceito na convivência social, apenas sofreu transformações formais de expressão" (Carone, 2002, p. 23). Assim, o que ocorre é que ele vai mudando e assumindo novas formas de expressões que não ameaçam o status quo. E para que isso ocorra, justificativas "não racistas" são utilizadas para camuflá-lo e, de certa forma, legitimá-lo, como já demonstrado na revisão feita por Pereira e Souza (2016). Na situação aqui apresentada, essa justificativa se baseia no fato que a competição é inerente ao futebol e, como consequência, as pessoas podem emitir julgamentos racistas sem, contudo, correrem o risco de serem julgadas de forma negativa. Dessa forma, cabe a investigações como a aqui apresentada desvelar as novas formas de expressão do preconceito para assim subsidiar estratégias e políticas públicas para combatê-lo.

\section{Referências}

Allport, G. W. (1954). The nature of prejudice. Cambridge, MA: Addison-Wesley.

Álvaro, J. L., Morais, T., Torres, A. R. R., Pereira, C. R., Garrido, A., \& Camino, L. (2015). The role of values in attitudes towards violence: discrimination against Moroccans and Romanian Gypsies in Spain. The Spanish Journal of Psychology, 18, 63-12. doi: 10.1017/ sjp.2015.65

Barradas, M. S. S., \& Lopes, O. G. (2013). Dribladores: passes e impasses do racismo no futebol carioca. Mnemosine, 9(1), 245-263.

Batista, J. R. M., Leite, E. L., Torres, A. R. R., \& Camino, L. (2014). Negros e Nordestinos: similaridades nos estereótipos raciais e regionais. Psicologia Política, 14(30), 325-345. Recuperado de http://pepsic.bvsalud.org/scielo.php?script=sci_arttext\&pi$d=S 1519-549 \times 2014000200008 \&$ Ing=es\&nrm=iso\&tlng=pt

Bergere, J. A. (1996). Psicología Social de los procesos migratorios y relaciones intergrupales. In J. L. Álvaro, A. Garrido, \& J. R. Torregrosa (Orgs.), Psicología Social Aplicada (p. 269). Madrid: McGraw-Hill.

Blumer, H. (1958). Race prejudice as a sense of group position. Pacific Sociological Review, 1(1), 3-8. doi: 10.2307/1388607

Brewer, M. B. (1994). The psychology of prejudice: getting it all together. In M. Zanna \& J. Olson (Org.), The psychology of prejudice: the Ontario symposium on personality and social psychology (p. 371). Hillsdale, NJ: Erlbaum.

Brown, R. J. (2010). Prejudice: its social psychology. Malden, Massachusetts, USA: Blackwell Publishers Inc.

Camargo, B. V., \& Justo, A. N. (2013). Tutorial para uso do software de análise textual IRAMUTEQ. Recuperado de http://www.iramuteq. org/documentation/fichiers/tutoriel-en-portugais

Camino, L., Álvaro, J. L., Torres, A. R. R., Garrido, A., Morais, T., \& Barbosa, J. (2013). Explaining social discrimination: racism in Brazil and xenophobia in Spain. Spanish Journal of Psychology, 16, 1-13. doi:10.1017/sjp.2013.65

Camino, L., Da Silva, P., Machado, A., \& Pereira, C. (2001). A face oculta do racismo no Brasil: uma análise psicossociológica. Revista Psicologia Política, 1(1), 13-36. Recuperado de http://www.fafich. ufmg.br/ psicopol/psicopol/artigos_pub/artigo_4.pdf

Camino, L., Gouveia, M. L., Maia, L., Paz, M. M., \& Santos, M. L. (2013). Repertórios discursivos contemporâneos sobre as desigualdades raciais no Brasil: um estudo com estudantes paraibanos de 
pós-graduação. Psicologia e Sociedade (Impresso), 25, 113-122. doi: 10.1590/S0102-71822013000100013

Camino, L., Tavares, T. L., Torres, A. R. R., Álvaro, J. L., \& Garrido, A. (2014). University students' discursive repertoires about racial quotas in brazilian public universities. Psicologia \& Sociedade, $26(\mathrm{n}$. spe), 117-128. doi: 10.1590/S0102-71822014000500013

Carone, I. (2002). Breve histórico de uma pesquisa psicossocial sobre a questão racial brasileira. In I. Carone \& M. A. S. Bento (Orgs), Psicologia social do racismo (p. 13). Petrópolis: Vozes

Cervi, T. A. N. (2014). Intolerância e racismo no futebol: a racialização do outro. ComCiência, 159. Recuperado de http://www.comciencia. $\mathrm{br} /$ comciencia/handler. php? section $=8 \&$ edicao $=100 \& \mathrm{id}=1222$

Devine, P. G., Plant, E. A., \& Blair, I. V. (2003). Classic and contemporary analyses of racial prejudice. In S. Gaertner \& R. Brown (Orgs.), Blackwell handbook of social Psychology: intergroup process ( $p$. 198). Oxford: Blackwell Publishing Company.

Doise, W. (1990). Les représentations sociales. In R. Ghiglione, C. Bonnet, \& J. F. Richard (Orgs.), Traité de psychologie cognitive (pp. 111-174). Paris: Dunod.

Dunning, E., \& Elias, N. (1992). A busca da excitação. Lisboa: Difel.

Ferreira, A. S. S., Leite, E. L., Muniz, A. S., Batista, J. R. M., Torres, A. R. R., \& Estramiana, J. L. A. (2017). Insult or prejudice: a study on the racial prejudice expression in football. Psico Porto Alegre, 48(2), 81-88. doi: 10.15448/1980-8623.2017.2.25170

Giglio, S. S., Tonini, M. D., \& Rubio, K. (2014). "Do céu ao inferno": a história de Baiano no Boca Juniors e os racismos no futebol. Projeto História, 49, 1-34. Recuperado de https://revistas. pucsp.br/index. $\mathrm{php/revph/article/view/19748}$

Guimarães, A. S. A. (1999). Racismo e anti-racismo no Brasil. São Paulo: Editora 34.

Guimarães, A. S. A. (2002). Classes, raças e democracia. São Paulo: Editora 34.

Helms, J. E., \& Talleyrand, R. M. (1997). Race is not ethnicity. American Psychologist, 52(11), 1246-1247. doi: 10.1037/0003-066X.52.11.1246

Instituto Brasileiro de Geografia e Estatística (2014). Síntese dos indicadores sociais: uma análise das condições de vida da população brasileira. Rio de Janeiro: Autor.

Jones, J. M. (1997). Prejudice and racism ( $2^{\mathrm{a}}$ ed.). Nova lorque: McGraw-Hill.
Lima, M. O., \& Vala, J. (2004). As novas formas de expressão do preconceito e do racismo. Estudos de Psicologia, 9, 401-411. doi: 10.1590/S1413-294X2004000300002

Lima-Nunes, A. V., \& Camino, L. (2011). Atitude político-ideológica e inserção social: fatores psicossociais do preconceito racial? Revista Psicologia \& Sociedade, 23(1), 135-143. doi: 10.1590/ S0102-71822011000100015

Munanga, K. (2001). Políticas de ação afirmativa em benefício da população negra no Brasil: um ponto de vista em defesa de cotas. Sociedade e Cultura, 4(2), 31- 42. doi: 10.5216/sec.v4i2.515

Pereira, C. R., \& Souza, L. E. C. (2016). Fatores legitimadores da discriminação: uma

revisão teórica. Psicologia: Teoria e Pesquisa (Online), 32(2), 1-10.

doi: 10.1590/0102-3772e322222

Potter, J., \& Wetherell, M. (1987). Discourse and social psychology: beyond the attitudes and behaviour. Londres: Sage.

Ratinaud, P. (2009). IRAMUTEQ: Interface de R pour les Analyses Multidimensionnelles de Textes et de Questionnaires.Computer software. Recuperado de http://www.iramuteq.org

Rodriguez, A. (1996). Psicología social de los prejuicios. In J. L. Álvaro, A. Garrido, \& J. R. Torregrosa, Psicología social aplicada (pp. 295). Madrid: McGraw-Hill.

Santos, N., Capraro, A. M., \& Lise, R. S. (2010). Racismo e a derrota que não foi esquecida: uma análise dos discursos de Mário Filho e da imprensa escrita acerca da final da Copa do Mundo de 1950 Movimento, 16(4), 191-208. Recuperado de http://www.seer.ufrgs. br/index.php/Movimento/article/view/15923/10851

Santos, T. C. (2014). A Campanha \#somostodosmacacos de Neymar: uma reflexão sobre o racismo no futebol. $4^{\circ}$ Congresso Internacional de comunicação e consumo, São Paulo, SP. Recuperado de http:// www.espm.br/download/Anais_Comunicon_2014/gts/gt_nove/ GT09_TARCYANIE_SANTOS.pdf

Schucman, L. V. (2014). Sim, nós somos racistas: estudo psicossocial da branquitude paulistana. Psicologia \& Sociedade, 26(1), 83-94 doi: 10.1590/S0102-71822014000100010

Telles, E. E. (2003). Racismo à brasileira: uma nova perspectiva sociológica. Rio de Janeiro: Relume-Dumará.

Turra, C., \& Venturi, G. (1995). Racismo cordial: a mais completa análise sobre preconceito de cor no Brasil. São Paulo: Ática.

Wetherell, M., \& Potter, J. L. (1996). El análisis del discurso y la identificatión de los repertorios interpretativos. In A. J. Gordo \& J. L. Linaza (Orgs.), Psicologías, discursos y poder (pp. 63-78). Madrid: Visor.

1. Este trabalho contou com bolsa de mestrado da Capes/DS para primeira autora e bolsa PIBIC/CNPq para a terceira autora, ambas sob orientação da última autora. 
Andreza Silene Silva Ferreira, Mestre em Psicologia Social pela Universidade Federal da Paraíba (UFPB), Estudante de doutorado no Programa de Pós-Graduação em Psicologia Social da Universidade Federal da Paraíba (UFPB). Endereço para correspondência: Rua Paulo de Araújo de Oliveira. $N^{\circ} 124$. Bairro Valentina de Figueiredo. João Pessoa - PB. CEP 58064-270.

Telefone: (83) 99807.8943. E-mail: andrezasilferr@gmail.com

Eldo Lima Leite, Mestre em Psicologia Social pela Universidade Federal da Paraíba (UFPB), é Doutorando no Programa de PósGraduação em Psicologia Social da Universidade Federal da Paraíba

(UFPB). E-mail: eldolima@gmail.com

Amanda Wanderley Leite de Sousa, Aluna do curso de graduação em Psicologia da Universidade Federal da Paraíba (UFPB), é bolsista PIBIC-CNPq. E-mail: amandasousa.910@gmail.com

José Luis Álvaro Estramiana, Doutor em Psicologia Social pela Universidad Complutense de Madrid (UCM), é Professor Catedrático de Psicologia Social do Departamento de Psicología Social da Universidad Complutense de Madrid (UCM). E-mail: jlalvaro@cps.ucm.es

Ana Raquel Rosas Torres, Doutora em Psicologia pela University of Kent at Canterbury (UKC, Reino Unido), Pós-doutorado em Psicologia Social na Université de Provence (UP, França), é Professora Associada do Departamento de Psicologia da Universidade Federal da Paraíba (UFPB) atuando na graduação e no Programa de Pós-Graduação em Psicologia Social da Universidade Federal da Paraíba (UFPB). E-mail: arr.torres@gmail.com

Recebido em 20.Set.16 Revisado em 02.Jun.17 Aceito em 02.Ago.17 